\title{
Preliminary Investigations of Structure and Properties of TIG Welded Ti-6Al-4V Alloy
}

\author{
Saurabh Dewangan ${ }^{*}$, Raushan Ranjan ${ }^{1}$, Somnath Chattopadhyaya ${ }^{2}$, \\ Deepak Gope ${ }^{2}$, Marta Bogdan-Chudy ${ }^{3}$
}

1 Department of Mechanical Engineering, School of Automobile, Mechanical and Mechatronics Engineering, Manipal University Jaipur, Dehmi Kalan, Jaipur, Rajasthan, India

2 Department of Mechanical Engineering, Indian Institute of Technology, Dhanbad, India

3 Faculty of Mechanical Engineering, Opole University of Technology, ul. Mikolajczyka 5, 45-271 Opole, Poland

* Corresponding author's email: saurabh22490@gmail.com

\begin{abstract}
The titanium (Ti) and its alloys are taken into interest for commercial purpose due to its low density, high yield strength and high corrosion resistance properties. The present work deals with microstructural observation and mechanical property analysis of tungsten inert gas (TIG) welded Ti-6Al-4V alloy joints. For the purpose, two different set of plates were welded at same current and voltage, i.e., $190 \mathrm{~A}$ and $24 \mathrm{~V}$, by the TIG welding technique. A critical analysis of the microstructure and mechanical properties like tensile strength and hardness of the welded Ti-6Al-4V plates was carried out in this work. It was found that both plates showed different behavior during the tension test. Plate 1 had $464.54 \mathrm{MPa}$ of tensile stress and it broke at the welded joint. Plate 2 was unaffected at the welded zone but was broken at the base metal zone. The second plate had tensile strength of $501.83 \mathrm{MPa}$. According to the hardness test, both the welded plates possessed the highest hardness at the welded zone. However, plate 2 showed approximately $10 \%$ higher hardness than that of plate 2 . A proper inter-relationship was observed between the mechanical behavior and microstructural appearance. The microscopic view of the welded joints revealed the presence of $\alpha, \beta$ and martensitic- $\alpha$ phases.
\end{abstract}

Keywords: Ti-6Al-4V titanium alloy; TIG welding; microstructural analysis; tensile test; hardness test

\section{INTRODUCTION}

Ti-alloys are widely used for industrial purposes. They exhibit a beneficial combination of strength, impact toughness, hardness and resistance to corrosion. The main characteristic of the Ti-alloys is very high strength to density ratio. Due to their light weight, they are usually applied in aerospace industries. Besides, Ti-alloys are also highly suitable for manufacturing various products like discs, rings, fasteners, fans, and various parts of jet engines in the automobile and chemical industries. Titanium can be used at an elevated temperature (nearly up to $650^{\circ} \mathrm{C}$ ) with an ideal level of reliability [1,2]. Ti-alloys can be distinguished by their constituents. They can be categorized in four ways: (1) pure titanium, (2) $\alpha$ phase-titanium, (3) $\alpha+\beta$ phase-titanium, (4) high $\beta$ phase-titanium. Pure titanium is generally not used for engineering purpose, although it has good weldability. It imparts a very little amount of $\mathrm{O}, \mathrm{C}, \mathrm{N}$ and $\mathrm{Fe}$. If the pure titanium is alloyed with aluminum (up to 7\%), it converts into $\alpha$ phase-titanium. Other elements like oxygen, nitrogen and carbon are also added along with aluminum to form $\alpha$ phase-alloy. When the elements like vanadium $(\mathrm{V})$, chromium $(\mathrm{Cr})$ and molybdenum (Mo), called $\beta$ forming elements, are added to the $\alpha$ phase-alloy, the mixture becomes $\alpha+\beta$ phase-titanium alloy. If the $\beta$ forming elements are added in large amount, weldability decreases remarkably. These alloys contain 
$\beta$-phase rich Ni-Ti alloys [3]. For majority of engineering works, the titanium alloy with $\alpha+\beta$ phase is preferred $[4,5]$. Ti- $6 \mathrm{Al}-4 \mathrm{~V}$ is the commercially available and is the most widely used $\alpha+\beta$ titanium alloy. It is also called grade- 5 alloy [6]. It imparts a beneficial combination of yield strength, wear resistance, weldability and hardness [7]. The properties of Ti-6Al-4V alloys have been discussed very well. As these alloys impart good amount of tensile strength, fatigue strength and high corrosion resistance, they are highly demanded in jet engine structural industry and petrochemical plants [8]. By the virtue of existence of two different phases i.e. $\alpha+\beta$ phases, grade- 5 alloy has both good amount of ductility and high hardness. The $\alpha$-phase can exist up to a temperature level of $882^{\circ} \mathrm{C}$. As soon as the temperature goes beyond $882^{\circ} \mathrm{C}$, the closely packed structure of $\alpha$-phase converts into the body centered cubic structure of $\beta$-phase [2]. This phenomenon takes place in welded titanium plates. The welding of titanium alloys can be done suitably by using the TIG welding method. Other techniques which produce comparatively lesser heat can also be used, for example: friction welding, electron beam welding, laser beam welding, diffusion welding, etc. [9]. In this regard, Short has explained that laser beam welding (LBM) technique is the best way to weld titanium alloys, although it is an expensive method. However, the TIG welding technique can also be effectively used as an alternative to LBM [10]. TIG is the best welding method to join relatively thin plates (up to $9.5 \mathrm{~mm}$ thickness) of metals. Many metals that are difficult to weld through other fusion welding approaches can be fabricated by TIG. No slag is produced in this method and therefore the defects like slag inclusion is eliminated in TIG $[11,12]$. Many research works related to titanium welding and its analysis were already done in the past. Some of them were discussed here comprehensively.

The TIG welding of Grade-5 Ti-alloy was performed with the similar metal. The aim was to reveal the inter-relationship between microstructure and mechanical properties after performing welding under two different conditions: with pulsating current and without pulsating current. The pulsed current condition critically enhanced the mechanical properties like hardness and ductility [13]. It was reported by that the pulsating current affected the toughness of the T-64 alloy [1]. Bendikiene et al. compared three different modes of TIG welding applied to weld pure titanium plates available commercially. These modes are: (1) welding under the full presence of argon inert gas by using tracks and shielding tools; (2) pulsed welding in a short interval; (3) conventional TIG welding. It was reported that the welding process by using tracks and shielding tools in presence of high amount of inert gases was the best way to weld titanium, as this process was characterized by higher stability than others. In addition, the destructive and non-destructive tests showed a very good result for the welded joint done by this method [14]. Chamanfar et al. investigated the microstructure and mechanical properties of the laser welded Ti1023 alloy. It was noticed that the primary $\alpha$ phase converted into $\beta$ phase across the welded plate. The fusion zone showed a complete conversion of $\alpha$ phase into $\beta$ phase, whereas the heat affected zone included a comparatively lesser amount of $\alpha$ to $\beta$ conversion. It was reported that the hardness of the base metal was greater than the heat affected zone and fusion zone due to possessing $\alpha$ primary phase in high amount. In addition, the yield strength and ultimate tensile strength were found to decrease at the fusion zone [15]. The heat and processing methods highly affect the microstructure and mechanical properties of the Ti-alloys. Therefore, they are the key factors to decide the final properties of the alloy [16, 17]. It was investigated by Min et al. that the increase in heat input could enhance the width of heat affected zone. In the case of Mg alloyed with $\mathrm{Ti}$, the welded zone and heat affected zones had coarse grains of $\alpha-\mathrm{Mg}$ phase [18]. Maawad et al. reported the microstructure and mechanical properties of the laser beam welded Ti-alloys [19]. In addition, welding of dissimilar grades of Ti-alloys e.g. Ti-15V-3Cr-3Al-3Sn with Ti-6AL-4V [20], Ti-alloys with nickel based alloys [21] and Ti-alloys with 304 grade stainless steel [22] were also reported in previous literature. Gao et al. performed the fracture toughness test on friction stir welded Ti-alloy joints. The welded joint was found to have almost $90 \%$ fracture toughness with respect to base metal. The welded zone had fine $\alpha$ phases. The fracture was mainly inter-granular in nature [23]. A complex thermal gradient was also reported during the TIG welding of Ti-6Al-4V alloy. The Ti-alloys showed a very fast cooling at the welded joint. This heating and cooling variation significantly affected the mechanical 
behavior as well as microstructures $[2,4]$. After an experiment of welding of 304L austenitic stainless steel/Incoloy 800HT nickel alloy, it was found that the joint had good mechanical and microstructural attributes as compared with the base metal parts [24]. The orbital TIG welded titanium tubes with bottom made up of Ti-clad steel showed a satisfactory result when tested under non-destructive and macrographic tests [25]. The hydroxyapatite coating was performed on laser modified Ti13 Nb13Zr alloy by using electrophoretic deposition. The coating thickness was reported from $4.06 \pm 0.76 \mu \mathrm{m}$ to $9.05 \pm 1.05 \mu \mathrm{m}$. The modified surface layer was reported to have lesser roughness [26]. Ti6Al4V (Grade 5) titanium alloy was taken under study for the tribological property analysis at room temperature and at elevated temperature of $150^{\circ} \mathrm{C}$. A ball-on-disc apparatus was used for this purpose. It was found that the ball had a higher wear rate at room temperature than at elevated temperature [27]. The surface layer development on HS 6-5-2 steel by carbonitriding and carbonitriding with oxidation methods was analyzed. A significant improvement in surface hardness was reported after carbonitriding [28]. Dental materials like CeramX and I-Light were also tested for the tribological and mechanical properties. A12O3 balls were selected as counter-body for the test. Satisfactory results were observed after experimentation [29].

Nowadays, the research work to investigate a wide range of material behaviors under different operational conditions like welding [30, 31], $\mathrm{CNC}$ lathe machining [32], heat treating [33, 34], etc., is underway. In addition, worldwide increasing applications of Ti-alloys, especially in chemical plants and aerospace industries, makes the on-going research work necessary. In the present work, an attempt was made to study the microstructure variation in Ti-6Al-4V alloys after welding. Moreover, variation of tensile strength and hardness of the welded specimen was discussed.

\section{MATERIALS AND METHOD}

The experimental work concerns the TIG welding phenomena of thin Ti-6Al-4V alloy plates. Two such pairs of plates have been welded. Each plate has a dimension of $100 \mathrm{~mm}$ length, $50 \mathrm{~mm}$ width and $3 \mathrm{~mm}$ thickness. As this grade of Ti-alloy is a commercially available, the plates have been purchased directly from the manufacturing industry. Due to its typical chemical composition, the grade 5 alloys are hard and brittle below $500^{\circ} \mathrm{C}$ but as soon as the temperature is increased, the alloy gains ductility. The typical chemical composition and various mechanical properties of Ti-6Al-4V alloy are shown in tables 1 and 2, respectively. TIG 400 Mosfet DC Inverter Welding Machine was used for welding the plates. The tungsten electrode of $2 \mathrm{~mm}$ diameter was selected for the process. A random selection of yield parameters for welding was carried out i.e. $24 \mathrm{~V}$ and $190 \mathrm{~A}$ of arc voltage and welding current, respectively. A filler material of Ti-6Al-4V alloy was also used during welding. The diameter of the filler metal rod is $2 \mathrm{~mm}$. The welded zone was protected by applying inert gas (argon $>99 \%$ ) during welding. The gas identification number is Ar 5.0. According to BS EN 439, argon (>99\%) comes under I-1 designation [35]. The shielding gas was provided with a flow rate of $11.5 \mathrm{l} / \mathrm{min}$. After joining, the two welded plates were named plate 1 and plate 2 .

As both the welded plates were analyzed for microstructure, strength and hardness, the required procedures of sample preparation were followed prior to testing. Three samples were cut from each welded plate. The first sample was used for the microstructural analysis, the second sample was used for tensile test and the third sample was analyzed for its hardness. The sample, which was used for microstructure observation, was properly polished by using a polishing machine and polishing papers of 500, 1000 and 2000 grit sizes. The cross-sectional parts of the plates

Table 1. Chemical composition of Ti-grade 5 alloy

\begin{tabular}{|c|c|c|c|c|c|c|c|}
\hline Elements & Carbon $(\mathrm{C})$ & Iron $(\mathrm{Fe})$ & Nitrogen $(\mathrm{N})$ & Oxygen $(\mathrm{O})$ & Aluminium(Al) & Vanadium $(\mathrm{V})$ & Titanium $(\mathrm{Ti})$ \\
\hline Weight $\%$ & 0.08 & 0.25 & 0.05 & 0.20 & $5.50-6.75$ & $3.5-4.5$ & Bal. \\
\hline
\end{tabular}

Table 2. Mechanical properties of Ti-grade 5 alloy

\begin{tabular}{|c|c|c|c|c|c|c|}
\hline Parameters & Yield strength & $\begin{array}{c}\text { Ultimate tensile } \\
\text { strength }\end{array}$ & Elongation & Hardness & $\begin{array}{c}\text { Modulus of } \\
\text { elasticity }\end{array}$ & Fatigue strength \\
\hline Typical values & $950 \mathrm{MPa}$ & $1020 \mathrm{MPa}$ & $14 \%$ & $36 \mathrm{HRC}$ & $120 \mathrm{GPa}$ & $510 \mathrm{MPa}$ \\
\hline
\end{tabular}


were polished to observe the microstructure. An etchant preparation is necessary after polishing of the sample. Etchant is a chemical/ mixture of chemicals which is applied on the polished surface prior to the microstructure observation. Etchant removes the oxide layers on the polished surface and allows the microstructures become exposed on the surface. Kroll's reagent is an appropriate etchant for Ti-alloys. Therefore, it was taken under study. It contains $92 \mathrm{ml}$ of distilled water, $6 \mathrm{ml}$ of nitric acid and $2 \mathrm{ml}$ of hydrofluoric acid. For the tension test and the hardness test, the standard sized specimens were prepared to obtain satisfactory results. The specimens were preferably cut with the wire-electric discharge machining method.

\section{TESTING AND RESULT ANALYSIS}

Microstructure analysis: The microstructural observation requires prior surface preparation of the metal. As the cross sectional surfaces of the welded plates underwent microstructural observation, these surfaces were properly cleaned and polished. In this work, n Motic image plus optical microscope (made in Germany) was used. The previous studies revealed that $\alpha$ and $\beta$ are the two phases present in the Ti-alloys. The $\alpha$ - phase is usually characterized as a soft phase whereas the $\beta$ phase is known to possess high hardness [2, 6]. The different types of alloying elements in titanium are classified on the basis of their effects on $\alpha-\beta$ transformation temperature. On the basis of the solubility in the $\alpha$ and $\beta$ phases, the alloying elements are categorized under $\alpha$ or $\beta$ stabilizers. Aluminium, oxygen, nitrogen and carbon are known as strong stabilizers of $\alpha$-phase. Al is a substitutional element and others $(\mathrm{O}, \mathrm{N}, \mathrm{C})$ take interstitial positions. As the amount of these elements (solute) are increased, the transus temperature of titanium increases. Conversely, the $\beta$ stabilizers, such as, Vanadium, Molybdenum, Niobium, Iron, Chromium, Cobalt, Nickel, Silicon, etc., decrease the transus temperature [3]. Grade 5 alloy of titanium contains $6 \mathrm{Al}-4 \mathrm{~V}$, which means it is a $\alpha+\beta$ alloy. The transformation temperature of this alloy is lower than that of pure Ti. Moreover, the commercial grade of alloys contain an increased width of the $\alpha+\beta$ phase. As the Ti-alloy melts, it crosses the transformation temperature and the whole alloy converts into the $\beta$ phase. At the time of cooling, with $\mathrm{Al}$ and $\mathrm{V}$ solute contents, the single $\beta$ phase converts into a two phase $(\alpha+\beta)$ system at low rate. Further, nucleation of $\alpha$ and $\beta$ grain boundaries takes place. In this work, the welded joints were cooled in atmospheric air. Hence, the cooling rate can be assumed as the same for both the welded plates. The microscopic images of both the welded joints were captured at a same scale of $10 \mu \mathrm{m}$. Figs. 1 and 2 show the micrographs of plate 1 and plate 2, respectively. In this study, the above mentioned two different phases were observed in the fusion zone as well as in the heat affected zone.

With regard to Fig. $1(a, b)$, it can be seen that the $\beta$ phase has properly converted into $\alpha$ phase. Moreover, a large region of retained $\beta$ phase is present. These figures belong to the fusion zone (FZ) of the plate 1. It means that FZ consists a bi-model type microstructure where the $\alpha+\beta$ phases are evenly dispersed in the zone. For a clear recognition of the phases, it can be noted that all the bright (in color) structures show the $\alpha$-phase, whereas the $\beta$ phase has a dark appearance. The Ti-alloys are dense due to the presence of closed-packed hexagonal crystal structure of $\alpha$ phase. This HCP structure converts into a body-centered cubic crystal structure ( $\beta$-phase) when the alloy undergoes an allotropic transformation at nearly $882.5^{\circ} \mathrm{C}$.

A separate heat affected zone (HAZ) in plate 1 could be observed (Fig. $1 \mathrm{c}$ ). A clear view of HAZ is shown in Fig. 1 (d). The microstructure of HAZ is completely different and it can be easily recognized in the presence of FZ. Unlike FZ, the presence of $\alpha+\beta$ phase is not even. On the basis of an assumption, the platelets of the $\alpha$ phase are surrounded by $\beta$ phase boundaries.

The microstructures in plate 2 are completely different from plate 1. Although the FZ in plate 2 is similar to that of plate 1 , the characteristics of HAZ are completely different. As predicted, FZ imparts a bi-model $\alpha+\beta$ phase structure where a nearly globular $\alpha$-phase is surrounded by the $\beta$ phase boundary (Fig. 2 a, b). The HAZ in plate 2 shows a martensitic transformation. Although both the plates were cooled in atmospheric air, the formation of acicular martensitic $\alpha$ phase is observed in HAZ. The continuous $\alpha$ phase (needle-like structure) is formed due to preferential precipitation along the $\beta$ grain boundaries. These needle-shaped structures of $\alpha$ phase possess very less ductility and the material becomes very hard (Fig. 2 c, d). 
(a)

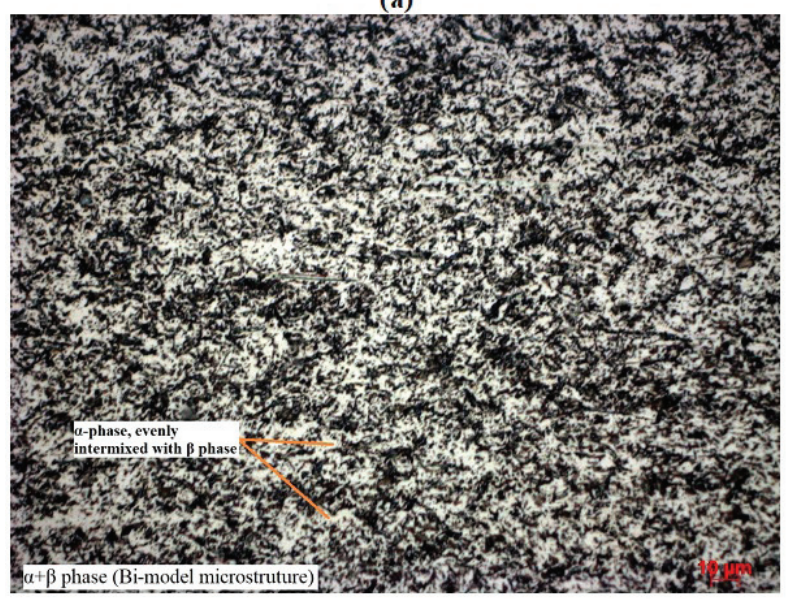

(c)

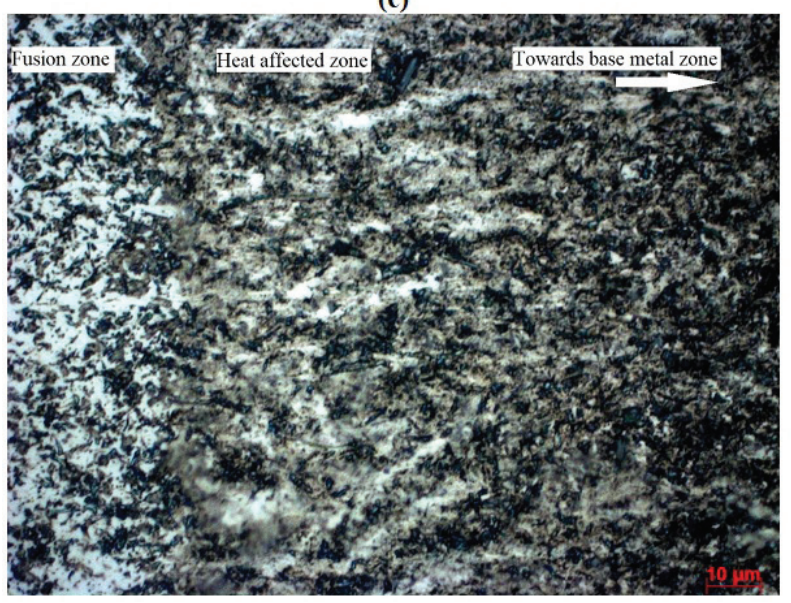

(b)

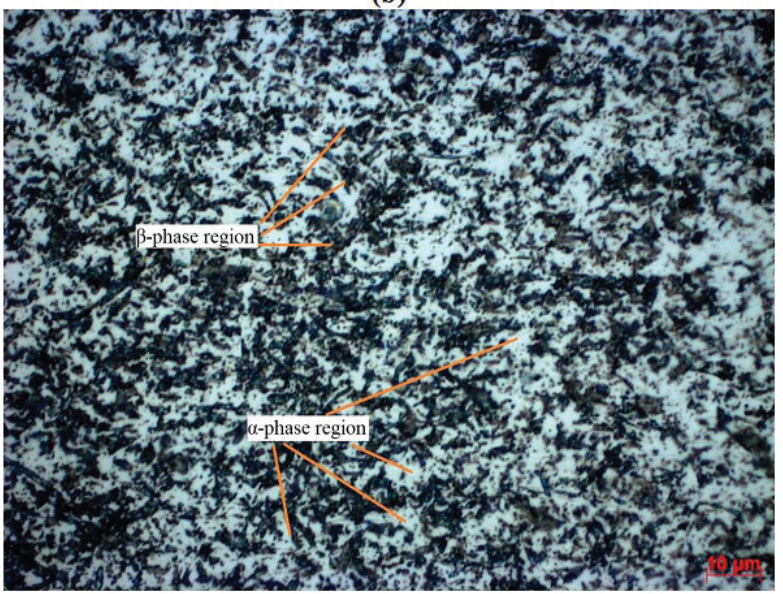

(d)

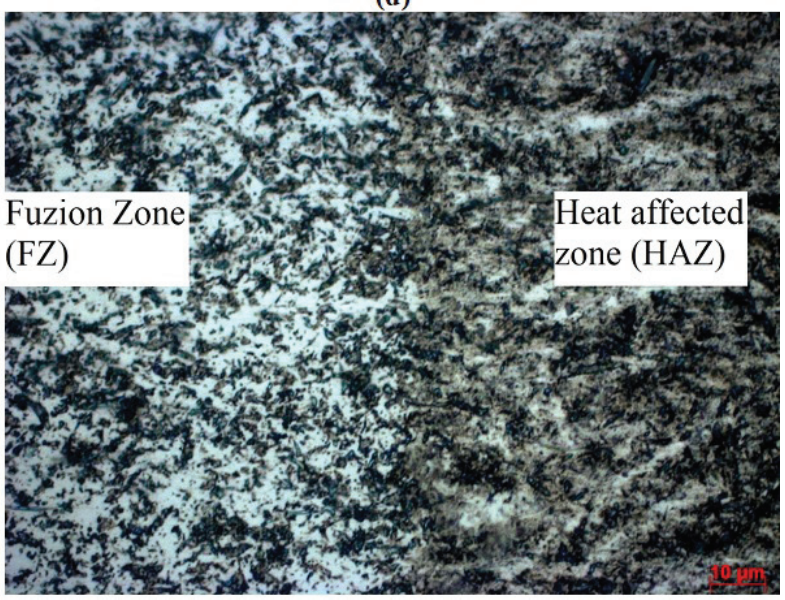

Fig. 1. Microstructure of welded plate 1; (a, b) bi-model microstructure in FZ; (c, d) a clear observation of HAZ

Tensile test: For performing this test, the samples were cut according to ASTM standard. The gauge length was kept approximately $45 \mathrm{~mm}$. The specimens used for this test are shown in Fig. 3(a). The tension test was conducted on a servo hydraulic controlled universal testing machine (company name: INSTRON 8800 UTM) which had the maximum capacity of $125 \mathrm{kN}$. An extensometer was used to control the strain rate in the process. A common strain rate of $0.001 \mathrm{~s}-1$ was selected for both the specimens. As soon as the load was applied, the material started to extend. The stress-strain diagram was automatically recorded by data acquisition system. After performing test, it was noticed that plate 1 was completely broken at the joint whereas the welded joint of plate 2 was unaffected. Plate 2 was broken through the base metal zone. A ductile failure was observed in plate 2. Both the tested specimens are shown in Fig. 3 (b). Also, the stress-strain graphs for the two specimens are shown in Fig. $4(a, b)$.

The ultimate tensile strength (UTS) of welded joint of specimen 1 was $464.54 \mathrm{MPa}$. The total elongation up to UTS point was $2.56921 \mathrm{~mm}$. Specimen 2, failed at base metal part, showed an UTS of $501.83 \mathrm{MPa}$ with an extension of $0.41585 \mathrm{~mm}$.

Both specimen 1 and specimen 2 showed different nature of the stress-strain curves. The tensile behavior of specimens corroborates with the microstructural results. The microstructural images of plate 1 showed a bi-model structure means $\alpha+\beta$ phases were evenly distributed at the welded portion. The $\alpha$ phase was reported as nearly globular in size which provided the ductility to the welded joint. In contrary, the micrograph of plate 2 had an acicular and martensitic $\alpha$-phase which made the welded joint very hard and relatively brittle. Therefore, the specimen 2 failed at the base metal part. This failure was ductile in nature.

Hardness test: Hardness was analyzed in both the plates by conventional Rockwell hardness test. In order to determine the exact profile of hardness in three different zones i.e. base metal, heat affected zone and fusion zone, this test was performed on the cross sectional surfaces of the 
(a)

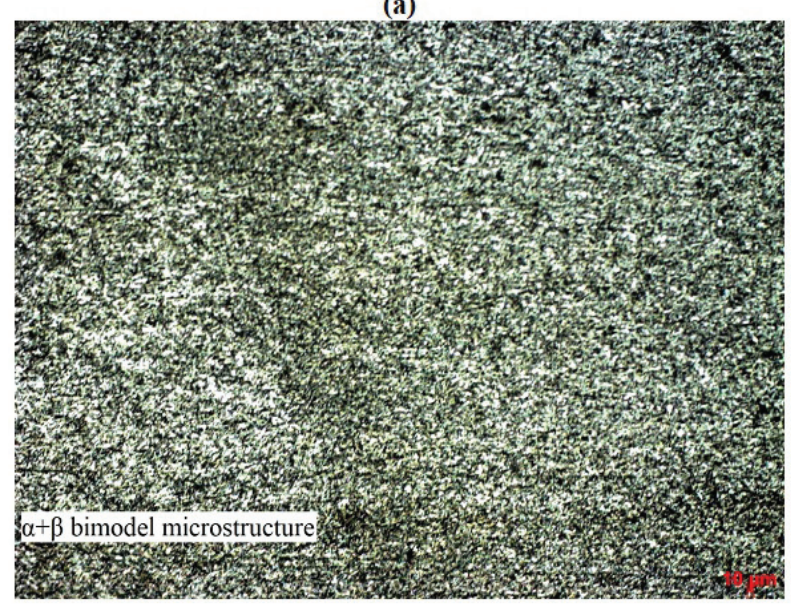

(c)

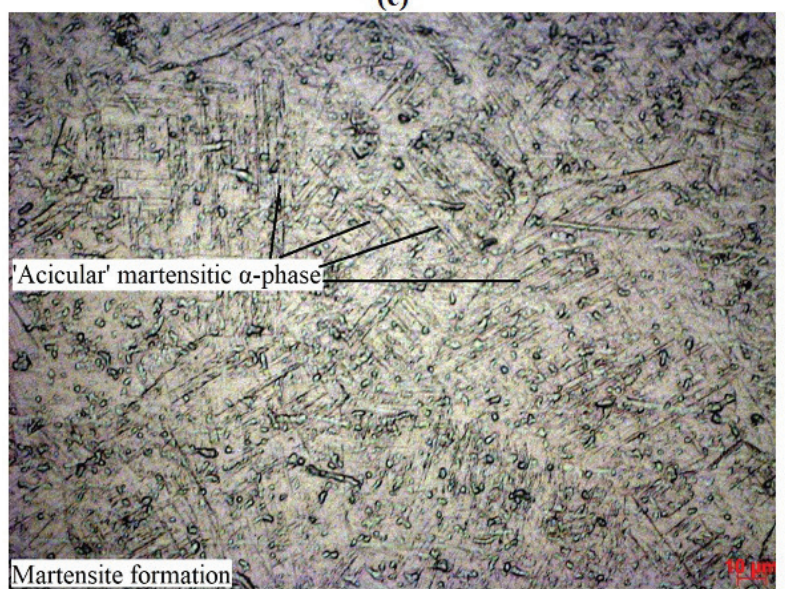

(b)

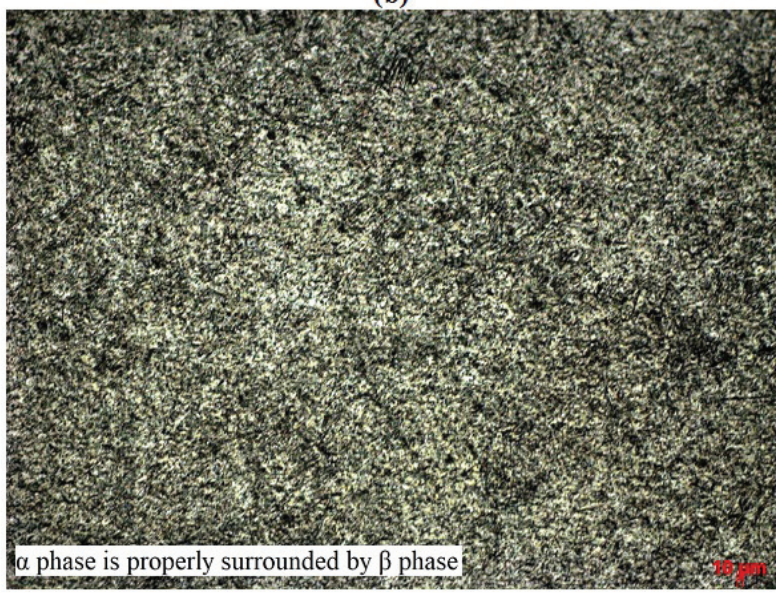

(d)

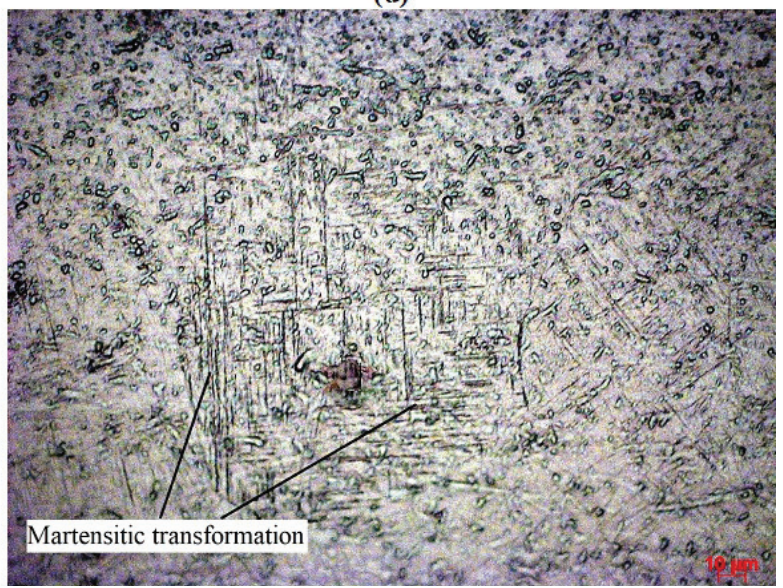

Fig. 2. Microstructures of Plate 2; (a) A bi-model $\alpha+\beta$ mixed phase was observed in fusion zone; (b) $\alpha$ phase is properly intermixed with $\beta$ phase; (c, d) Martensitic transformation was reported in HAZ, an acicular structure of $\alpha$ phase in the retained $\beta$ phase was observed

(a) Tensile test specimens

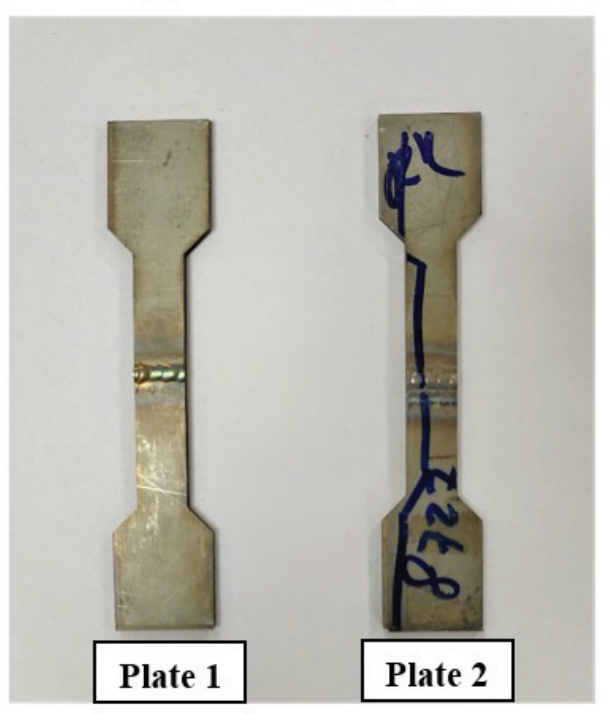

(b) Broken specimens after test

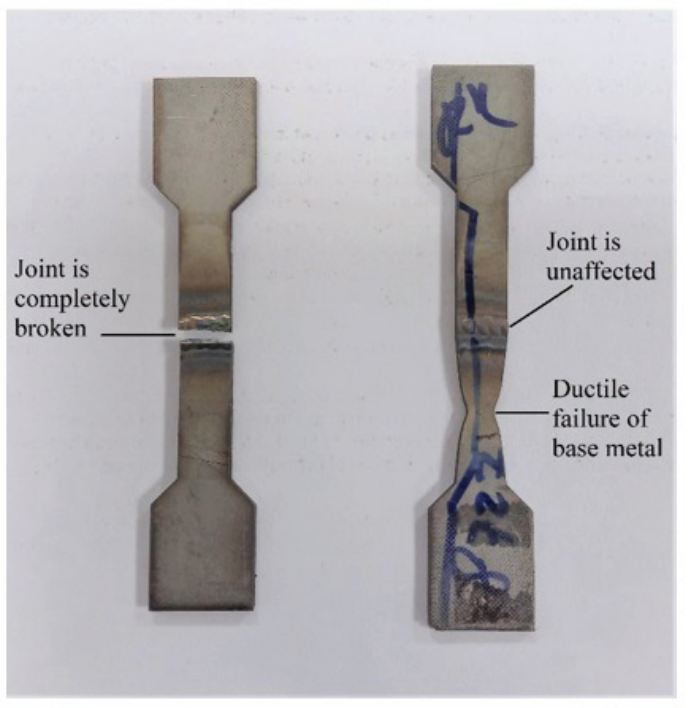

Fig. 3. (a) Tensile test samples, plate 1 and plate 2; (b) tested samples, plate 1 is completely broken at the joint and plate 2 has a ductile failure at base metal part with unaffected joint 
(a)

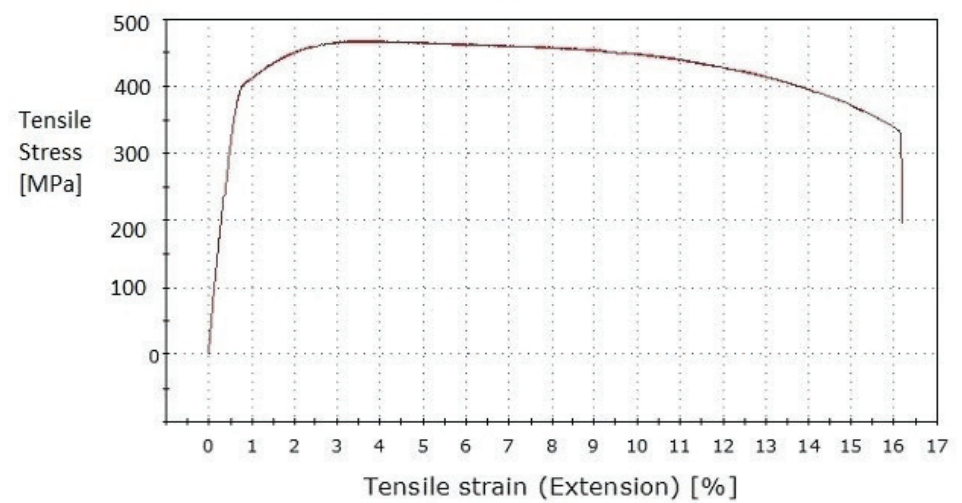

\begin{tabular}{|c|c|c|c|c|}
\hline Specimen & $\begin{array}{c}\text { Modulus (E- } \\
\text { modulus) } \\
{[\mathrm{GPa}]}\end{array}$ & $\begin{array}{c}\text { Extension at } \\
\text { Tensile strength } \\
{[\mathrm{mm}]}\end{array}$ & $\begin{array}{c}\text { Tensile stress at } \\
\text { Tensile strength } \\
{[\mathrm{MPa}]}\end{array}$ & $\begin{array}{c}\text { Load at Tensile } \\
\text { strength } \\
{[\mathrm{kN}]}\end{array}$ \\
\hline 1 & 61.92 & 2.47 & 464.54 & 13.94 \\
\hline
\end{tabular}

(b)

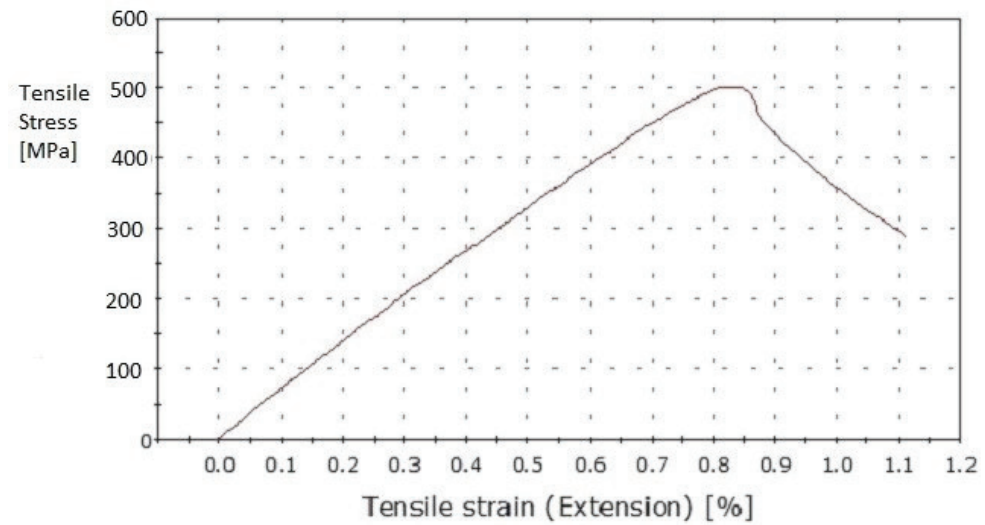

\begin{tabular}{|c|c|c|c|c|}
\hline Specimen & $\begin{array}{c}\text { Modulus (E- } \\
\text { modulus) } \\
{[\mathrm{GPa}]}\end{array}$ & $\begin{array}{c}\text { Extension at } \\
\text { Tensile strength } \\
{[\mathrm{mm}]}\end{array}$ & $\begin{array}{c}\text { Tensile stress at } \\
\text { Tensile strength } \\
{[\mathrm{MPa}]}\end{array}$ & $\begin{array}{c}\text { Load at Tensile } \\
\text { strength } \\
{[\mathrm{kN}]}\end{array}$ \\
\hline 2 & 63.92 & 0.42 & 501.83 & 15.05 \\
\hline
\end{tabular}

Fig. 4. Stress vs strain diagram of two specimens (a) plate 1; (b) plate 2

\section{Hardness test specimen 1}

Hardness test specimen 2

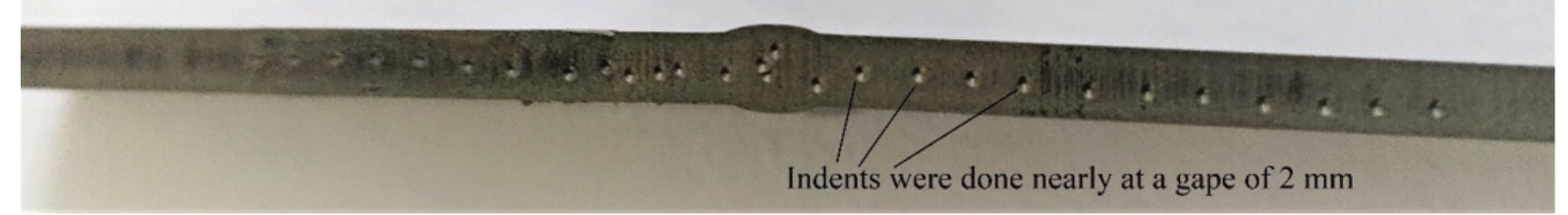

Fig. 5. Hardness test specimens 1 and 2; indents were made on both the specimens 


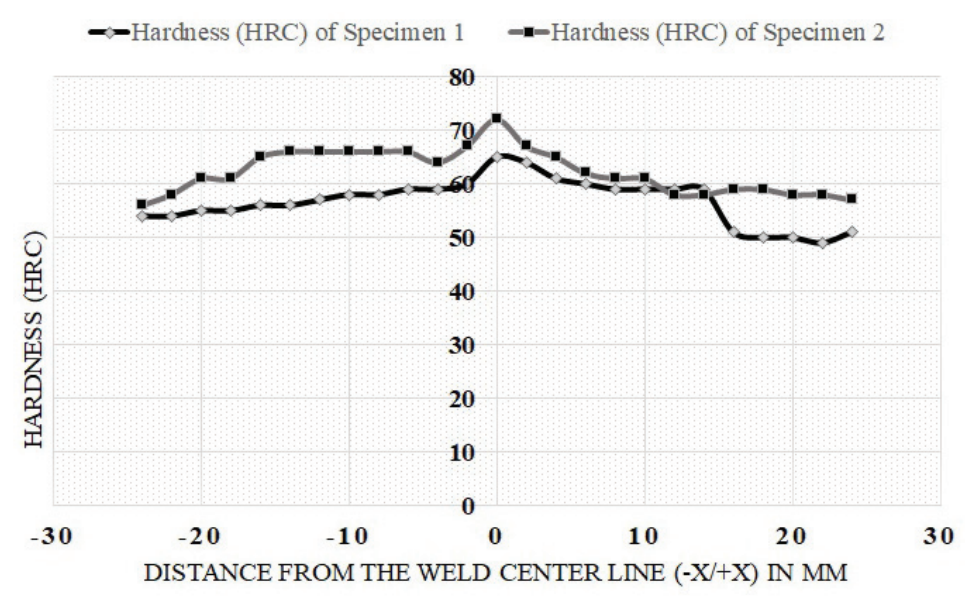

Fig. 6. Comparison of hardness between specimen 1 and specimen 2

welded plates. In this test, a diamond indenter was allowed to make indentation with $150 \mathrm{~kg}$ of load. A total of 25 indentations was made on each specimen. Out of these 25 indents, 1 indent was made at the weld center line, 12 indents were made at the left side of the center point and next 12 indents were performed at right side of the same. A gap of approximately $2 \mathrm{~mm}$ was maintained between two consecutive indents. The data related to the distance from the center line and Rockwell hardness values are given in table 1 . On the basis of the result obtained by hardness test, a graph between hardness and distance from weld center line was drawn. The two plates and their hardness profile are shown in Figs. 5 and6, respectively.

According to the hardness profiles of both the specimens (Fig. 6), the maximum hardness was achieved in the weld center line. This is the position of fusion zone (FZ). The hardness at the FZ in specimen 2 (72 HRC) is higher than that of specimen 1 ( $65 \mathrm{HRC}$ ). In addition to the FZ, all the indents in both sides of the specimen 2 show a comparatively higher values of hardness. Although the difference between the hardness of both specimens is not very high, the results can be compared with the outcome of microstructural analysis. As the formation of needle shaped structure (martensite) was reported in specimen 2, its hardness was found higher than the bi-model $(\alpha+\beta)$ structure of specimen 1. In both specimens, a common hardness profile at different zones was noted. In other words, the increasing order of hardness in three different zones of two given specimens are: Base metal $<$ Heat affected zone $<$ Fusion Zone. In general, the hardness results proved that the weld qualities of both joints are good.

\section{DISCUSSION}

Although the titanium alloys were extensively investigated for their critical properties [36, 37], still the scope of research in this field is quite large. In the present work, two different kinds of microstructures were reported even after processing through a common environment. Both plates were cooled in air, but one has the evidence of slow cooling rate and another proves for a fast cooling rate. Both plate 1 and plate 2 had the $\alpha$ and $\beta$ phases together. This result is similar to those of reported by [2] and [6]. The appearance of the $\alpha+\beta$ phases is almost globular, which establishes that the welded joint is ductile. However, another structure of acicular $\alpha$ (or martensite) in plate 2 proves that the high temperature $\beta$ phase does not have sufficient time to convert into equi-axed structure. This nature of material was found exceptional in the present work. Although the hardness test results satisfy with the outcomes of the micrographic observations, the hardness values are not up to the mark. As per the expectations, the martensitic $\alpha$ phase is too hard and relatively brittle. However, there is a difference of only 7 HRC (approximately 11\%) between the hardness values at fusion zones of specimen 1 and specimen 2. It may depend upon the selection of area under microscopic observation. In the same specimen, there may be two different microstructural behaviors at two different area of observations. In the case of tensile test, although all the experimental conditions for welding were same, the tension characteristics of both the specimens got changed. One specimen broke at the joint and another was unaffected at the area. It proves an old concept that the base metal may fail under external loading but a good welded joint may not. 
With the changing behavior of the metals, especially including Ti-alloys, a continuous research is necessary to unfold the material properties.

\section{CONCLUSIONS}

This work presents an analysis into the microstructural behavior and mechanical properties of TIG welded Ti-6Al-4V alloy plates. This alloy is a well-known commercial grade which is often called $\alpha+\beta$ Ti-alloy. Two different Ti-alloy plates were welded at same the current and voltage of $190 \mathrm{~A}$ and $24 \mathrm{~V}$, respectively. There was a random selection of current and voltage for welding, as the main aim of this work was to find an inter-relationship between microstructure and mechanical properties. It was found that Ti-6Al-4V had a good weldability if welded through TIG technique. A proper sample preparation and etchant application were done prior to microscopic observation. Moreover, the necessary preparation of samples for tensile test and hardness test was done. The results and outcomes of this work can be concluded as follows:

The microstructures of the welded joints of both the specimens showed different characteristics. Specimen 1 revealed mainly a bi-model structure, i.e., the $\alpha+\beta$ phases were evenly distributed in the overall welded zone. The $\alpha$ phase was observed in globular form at some places. Specimen 2 had an acicular martensitic structure of the $\alpha$ phase. It generally happens when the $\beta$ phase cools at a fast rate and it precipitates at the boundaries of the needle shaped $\alpha$ phase. This condition made the specimen 2 harder than specimen 1.

The tensile properties of the specimens were found comparable with the microstructures. Specimen 1, with a bi-model $\alpha+\beta$ phase, showed a defined yield strength, ultimate tensile strength and a failure stress. The UTS of specimen 1 was reported as 464.54 MPa. Specimen 2, having a martensitic $\alpha$ phase, did not break through the joint. However, the metal reached a ductile failure at the base metal part. It showed the UTS value of $501.83 \mathrm{MPa}$ which is approximately $8 \%$ higher than that of specimen 1 . However, the tensile behavior of both the specimens could not be compared, because they fractured at different points.

In hardness test, again the microstructural studies were corroborated with the hardness results of the specimens. Specimen 2, with martensitic $\alpha$ phase, was found almost $11 \%$ harder than specimen 1 . In both specimens, the hardness profiles are similar. In other words, hardness values were found to increase from the base metal zone to the welded zone. The maximum hardness was achieved at FZ, whereas the least hardness was reported at the base metal part. HAZ had lower hardness values than that of FZ but higher than the same of base metal part.

\section{REFERENCES}

1. Balasubramanian T.S., Balakrishnan M., Balasubramanian V., Manickam M.M. Influence of welding processes on microstructure, tensile and impact properties of Ti-6Al-4V alloy joints. Transactions of Nonferrous Metals Society of China. 2011; 21(6): 1253-1262.

2. Gope D.K., Kumar U., Chattopadhyaya S., Mandal $\mathrm{S}$. Experimental investigation of pug cutter embedded TIG welding of Ti-6Al-4V titanium alloy. Journal of Mechanical Science and Technology. 2018; 32(6): 2715-2721.

3. Lütjering G., Williams J.C., Gysler A. Microstructure and mechanical properties of titanium alloys. In Microstructure And Properties Of Materials. 2000; 2: 1-77.

4. Gope D.K., Kumar U., Chattopadhyaya S. Mandal S., Investigation into the TIG welded joint of titanium G-5 alloy sheet. IOP Conference Series: Materials Science and Engineering, Sikkim, India 2018; 377.

5. Józwik J., Ostrowski D., Milczarczyk R., Krolczyk $\mathrm{G}$. Analysis of relation between the 3D printer laser beam power and the surface morphology properties in Ti-6Al-4V titanium alloy parts. Journal of the Brazilian Society of Mechanical Sciences and Engineering. 2018; 40(215).

6. Kumar U., Gope D. K., Kumar R., Chattopadhyaya S., Das A.K., Pramanik A., Krolczyk G. Investigation of microstructure and mechanical properties of titanium alloy sheet using low power Nd-YAG laser welding process, Metallic Materials/Kovové Materiály. 2018;56(2):121-129.

7. Krolczyk G., Sedmak A., Kumar U., Chattopadhyaya S., Das A.K., Pramanik A. A study of heat-affected zone and mechanical properties of Nd-YAG laser welding process of thin titanium alloy sheet. Natural Resources \& Engineering. 2016; 1(2): 51-58.

8. Oh J., Kim N.J., Lee S., Lee E.W. Correlation of fatigue properties and microstructure in investment cast Ti-6Al-4V welds. Materials Science and Engineering: A. 2003; 340(1-2): 232-242.

9. Yunlian Q., Ju D., Quan H., Liying Z. Electron beam welding, laser beam welding and gas tungsten arc welding of titanium sheet. Materials Science and Engineering: A. 2000; 280(1): 177-181.

10. Short A.B., Gas Tungsten Arc welding of $\alpha+\beta$ titanium alloys: A review. Materials Science and Technology. 2009;25:309-324. 
11. Lienert T., Siewert T, Babu S., Acoff V. ASM Handbook, Volume 6A: Welding Fundamentals and Processes. ASM International; 1993.

12. Arivazhagan B., Vasudevan M. A study of microstructure and mechanical properties of grade 91 steel A-TIG weld joint. Journal of Materials Engineering and Performance. 2013; 22(12):3708-3716.

13. Babu N.K., Raman S.G.S., Mythili R., Saroja S. Correlation of microstructure with mechanical properties of TIG weldments of $\mathrm{Ti}-6 \mathrm{Al}-4 \mathrm{~V}$ made with and without current pulsing. Materials Characterization. 2007; 58(7): 581-587.

14. Bendikiene R., Baskutis S., Baskutiene J., Ciuplys A., Kacinskas T. Comparative study of TIG welded commercially pure titanium. Journal of Manufacturing Processes. 2018; 36: 155-163.

15. Chamanfar A., Huang M.F., T., Tsukamoto M., Misiolek W.Z. Microstructure and mechanical properties of laser welded $\mathrm{Ti}-10 \mathrm{~V}-2 \mathrm{Fe}-3 \mathrm{Al}$ (Ti1023) titanium alloy. Journal of Materials Research and Technology. 2020; 9: 7721-7731.

16. Donachie M.J. Titanium A Technical Guide, 2nd ed. ASM International; 2000.

17. Lütjering G., William J.C., Titanium. Springer-Verlag Berlin Heidelberg. New York; 2003.

18. Min G., Wei Y., Zhan X., Gu C., Yu F. A coupled thermal and metallurgical model for welding simulation of Ti-6Al-4V alloy. Journal of Materials Processing Technology. 2014; 214: 2434-2443.

19. Maawad E., Gan W., Hofmann M., Ventzke V., Riekehr S., Brokmeier H.G. Influence of crystallographic texture on the microstructure, tensile properties and residual stress state of laser-welded titanium joints. Materials \& Design. 2016; 101: 137-45.

20. Hsieh C.T., Shiue R.K., Huang R.T., Tsay L.W. The effect of post-weld heat treatment on the microstructure and notched tensile fracture of $\mathrm{Ti}-15 \mathrm{~V}-3 \mathrm{Cr}-3 \mathrm{Al}-3 \mathrm{Sn}$ to $\mathrm{Ti}-6 \mathrm{Al}-4 \mathrm{~V}$ dissimilar laser welds. Materials Science and Engineering: A. 2016;653:139-46.

21. Liu J., Liu H., Gao X.L., Yu H. Microstructure and mechanical properties of laser welding of Ti6Al4V to Inconel 718 using $\mathrm{Nb} / \mathrm{Cu}$ interlayer. Journal of Materials Processing Technology. 2020; 277: 116467.

22. Elmi Hosseini S.R., Feng K., Nie P., Zhang K., Huang J., Li Z. Enhanced strength of 304 SSTi6Al4V laser-welded joints containing composite interlayers. Journal of Materials Engineering and Performance. 2018; 27: 6135-48.

23. Gao F., Guo Y., Qiu S., Yu Y., Yu W. Fracture toughness of friction stir welded TA5 titanium alloy joint. Materials Science \& Engineering A, 2020; 776: 138962.

24. Rogalski G., Świerczyńska A., Landowski M., Fydrych D. Mechanical and Microstructural Characterization of TIG Welded Dissimilar Joints between 304L Austenitic Stainless Steel and Incoloy 800HT Nickel Alloy. Metals. 2020; 10: 559.
25. Górka J., Przybyła M., Szmul M., Chudzio A., Ładak D. Orbital TIG welding of titanium tubes with perforated bottom made of titanium-clad steel. Advances in Materials Science. 2019; 19(3): 55-64.

26. Jażdżewska M., Majkowska-Marzec B. Hydroxyapatite deposition on the laser modified Ti13Nb13Zr alloy. Advances in Materials Science. 2017; 17(4): 5-13.

27. Jozwik J. Evaluation of Tribological Properties and Condition of Ti6Al4V Titanium Alloy Surface. Tehnički Vjesnik. 2018; 25(1): 170-175.

28. Jozwik J., Dziedzic K., Usydus I., Raos P., Krolczyk G.M. HS 6-5-2 steel surface layer development in carbonitriding with zeroflow method. Tehnički Vjesnik. 2016; 23(5): 1405-1409.

29. Dziedzic K., Zubrzycka-Wróbel J., Józwik J., Barszcz M., Siwak P., Chałas R. Research on tribological properties of dental composite materials. Advances in Science and Technology Research Journal. 2016; 10(32): 144-149.

30. Dewangan S., Mohapatra S.K., Sharma A. An assessment into mechanical properties and microstructural behavior of TIG welded Ti-6Al-4V titanium alloy. Grey Systems: Theory and Application. 2020; 10(3): 281-292.

31. Dewangan S., Patel M.R., Singh R., Kumar A., Gope D.K., Kumar U. Temperature distribution analysis and hardness measurement into TIG welded stainless steel plates. AIP Conference Proceedings. 2019; 2148(1): 030043.

32. Józwik J., Semotiuk L., Kuric I., Diagnostic of CNC lathe with QC 20 ballbar system. Advances in Science and Technology Research Journal. 2015; 9(28): 96-102.

33. Dewangan S., Behera S., Chowrasia M.K. Comparative analysis into mechanical properties and microstructural attributes of quenched and tempered $0.2 \%$-C steel. World Journal of Engineering. 2020; 17(1): 127-133.

34. Dewangan S., Mainwal N., Khandelwal M., Jadhav P.S. Performance analysis of heat treated AISI 1020 steel samples on the basis of various destructive mechanical testing and microstructural attributes. Australian Journal of Mechanical Engineering. 2019: 1-14.

35. Shielding gases for arc welding and cutting (access: 18th November 2020). https:// www.twi-global.com/technical-knowledge/ published-papers/shielding-gases-for-arc-welding-and-cutting-may-2001

36. Welding of Titanium Alloys (access: 9th November 2020). http://www.totalmateria.com/Article28.htm

37. Kumar U., Gope D., Srivastava J., Chattopadhyaya S., Das A., Krolczyk G. Experimental and Numerical Assessment of Temperature Field and Analysis of Microstructure and Mechanical Properties of Low Power Laser Annealed Welded Joints. Materials. 2018; 11(9): 1514. 